\title{
Acute and Late Toxicity after Moderate Hypofractionation with Simultaneous Integrated Boost (SIB) Radiation Therapy for Prostate Cancer. A Single Institution, Prospective Study
}

\author{
Kliton Jorgo $^{1,2} \cdot$ Csaba Polgar ${ }^{1,2}$. Tibor Major ${ }^{1,2} \cdot$ Gabor Stelczer $^{1,3}$ - Andras Herein ${ }^{1,3}$ - Tamas Pocza ${ }^{1,3}$. \\ Laszlo Gesztesi ${ }^{1}$ - Peter Agoston ${ }^{1,2}$
}

Received: 27 November 2018 / Accepted: 19 February 2019/Published online: 19 March 2019

(C) The Author(s) 2019

\begin{abstract}
Asbtract
To evaluate the acute and late toxicity using moderately hypofractionated, intensity-modulated radiotherapy (IMRT) with a simultaneous integrated boost (SIB) to prostate for patients with intermediate and high risk prostate cancer. From 2015 to 2017, 162 patients were treated with IMRT with SIB to the prostate. IMRT plans were designed to deliver 50.4Gy in 28 fractions ( $1.8 \mathrm{~Gy} /$ fraction) to the pelvic lymph nodes (whole pelvis radiotherapy, WPRT) while simultaneously delivering 57.4 Gy in 28 fractions $(2.05 \mathrm{~Gy} /$ fraction) to the seminal vesicles and $70 \mathrm{~Gy}$ in 28 fractions ( $2.5 \mathrm{~Gy} /$ fraction) to the prostate for high risk patients. For intermediate risk patients the same technique was applied, without WPRT. Acute and cumulative late genitourinary (GU) and gastrointestinal (GI) toxicities were scored according to the Radiation Therapy Oncology Group (RTOG) scoring system. Of the 162 patients enrolled, 156 (96\%) completed the treatment as planned. The median follow-up time was 30 months. Seventy-eight patients (48.2\%) were treated with WPRT. The rate of acute grade $\geq 2$ GI and GU toxicities in all patients were $22 \%$ and $58 \%$, respectively. The rate of cumulative late grade $\geq 2$ GI and GU toxicities were $11 \%$ and $17 \%$, respectively. Acute grade 3 GI and GU toxicities occurred in 1\% and 1\%. Late grade 3 GI and GU side effects occurred in 5\% and 4\%, respectively. None of the patients developed grade $\geq 4$ toxicity. IMRT with SIB technique using moderate hypofractionation to the prostate is feasible treatment option for intermediate and high risk patients, associated with low rate of severe GU and GI toxicities.
\end{abstract}

Keywords Prostate cancer - Simultaneous integrated boost - Moderate hypofractionation · Intensity-modulated radiotherapy . Image-guided radiotherapy

\section{Introduction}

Several randomized trials have shown improved biochemical control with dose escalation for prostate cancer [1-3]. The $\alpha /$ $\beta$ ratio for prostate cancer is suggested to be lower than that of surrounding normal tissues, and may be as low as $1.5 \mathrm{~Gy}[4$,

Kliton Jorgo

jorgokliton@gmail.com

1 Centre of Radiotherapy, National Institute of Oncology, Budapest Ráth György utca 7-9, Budapest 1122, Hungary

2 Department of Oncology, Semmelweis University, Budapest Üllöi út 26, Budapest 1085, Hungary

3 Institute of Nuclear Technique, Budapest University of Technology and Economy, Budapest Müegyetem rakpart 3, Budapest 1111, Hungary
5]. According to this, the therapeutic outcome using external beam radiotherapy is expected to be improved with hypofractionation, in case of delivering higher biologically effective dose (BED) than with conventional external beam radiotherapy. As $\alpha / \beta$ ratio for rectum and urinary bladder is estimated to be 3Gy and 5-10Gy, respectively, the low $\alpha / \beta$ ratio ofprostate cancer theoretically allows dose escalation with hypofractionation without increasing late toxicity [6]. Beyond the advantages in terms of tumour control and late toxicity, the use of large dose per fraction is preferred by patients and may have important implications for costeffectiveness by shortening the overall treatment time. Several contemporary phase III, randomized trials with mature data have confirmed similar tumour control and late toxicity among various hypofractionated regimens to conventionally fractionated external beam radiotherapy [7] . Independently of the patients risk groups, except one trial, the treatment target volume was the prostate gland and \pm 
seminal vesicles without pelvic lymph nodes. The rational of elective whole pelvis radiotherapy (WPRT) in patients with high risk of subclinical lymph node involvement (Roach equation $\geq 15 \%$ ) is the possibility to improve loco-regional control [8]. In these high risk patients, surgical series with extended lymphadenectomy showed a considerable incidence (17$46 \%$ ) of microscopic disease in the pelvic lymph nodes [9-13]. Large, contemporary retrospective trials confirmed a statistically significant benefit in biochemical control with WPRT compared to prostate ( \pm irradiation of seminal vesicles) irradiation, only [14-19]. However, currently there is insufficient evidence to recommend routine use of WPRT for high risk patients. Three randomized trials have shown no benefits for WPRT with respect to disease-free survival or overall survival [20-22]. Since 2015 we have treated intermediate and high risk prostate cancer patients with image-guided, intensity modulated radiotherapy (IG-IMRT), using a simultaneous integrated boost (SIB) to the prostate for moderate hypofractionation. The aim of this phase II study was to evaluate the acute and late side effects after moderate hypofractionation with or without WPRT in combination with SIB technique to the prostate.

\section{Materials and Methods}

This prospective study was approved by our institutional ethical review board (68.2019). Patients with less than 12 months of follow up were excluded from the analysis. The main characteristics of the patients are shown in Table 1. Between January 2015 and March 2017, 162 patients with histologically confirmed adenocarcinoma of the prostate were enrolled in this trial. Before treatment a detailed medical history was recorded and physical examination including digital rectal examination was performed. A pretreatment bone scan and abdominal CT or MRI were required to stage the prostate cancer and to exclude distant metastases. Patients with prior pelvic irradiation, a history of collagen vascular or inflammatory bowel disease were also excluded. In accordance with D'Amico et al. [23], four risk groups were identified: low risk: $\leq \mathrm{cT} 2 \mathrm{a}$ and Gleason score $\leq 6$ andPSA $<10 \mathrm{ng} / \mathrm{mL}$; intermediate risk: cT2b and/or Gleason score 7and/or PSA 10-20 ng/ml; high risk: $\geq c T 2 c$ and/or Gleason score $\geq 8$ and/or PSA > $20 \mathrm{ng} / \mathrm{mL}$ and/or patients with $\mathrm{cN} 1$ disease. All patients participating in this study were intermediate or high risk or node positive. High risk and node positive patients received whole pelvic irradiation. According to our institutional protocol in high risk patients older than 70 years, considering the toxicity/ benefit ratio, prophylactic WPRT was not performed, in the lack of high level of evidence proving better biochemical control or disease free survival after WPRT. Intermediate risk patients with bulky disease or unfavourable histological parameters received neoadjuvant and concomitant hormone
Table 1 Patient, tumour and treatment characteristics

\begin{tabular}{|c|c|}
\hline Characteristic & $\mathrm{N}(\%)$ \\
\hline \multicolumn{2}{|l|}{ Age (years) } \\
\hline Median & 71 \\
\hline Range & $50-83$ \\
\hline TURP $^{1}$ before EBRT $^{2}$ & $19(11 ., 7 \%)$ \\
\hline \multicolumn{2}{|l|}{ T stage } \\
\hline $\mathrm{T} 1-2$ & $110(68 \%)$ \\
\hline $\mathrm{T} 3$ & $48(30 \%)$ \\
\hline $\mathrm{T} 4$ & $4(2 \%)$ \\
\hline \multicolumn{2}{|l|}{$\mathrm{N}$ stage } \\
\hline No & $140(86 \%)$ \\
\hline N1 & $22(14 \%)$ \\
\hline \multicolumn{2}{|l|}{ Gleason score } \\
\hline$\leq 6$ & $33(20 \%)$ \\
\hline 7 & $61(38 \%)$ \\
\hline$\geq 8$ & $68(42 \%)$ \\
\hline \multicolumn{2}{|l|}{ Initial PSA } \\
\hline Median & 18 \\
\hline Range) & $2-400$ \\
\hline$<10$ & $49(30 \%)$ \\
\hline $10-20$ & $39(24 \%)$ \\
\hline$\geq 20$ & $74(46 \%)$ \\
\hline \multicolumn{2}{|l|}{ Risk groups } \\
\hline Intermediate & $34(21 \%)$ \\
\hline High or lymph node positive & $128(79 \%)$ \\
\hline \multicolumn{2}{|l|}{ Hormonal therapy } \\
\hline No & $16(10 \%)$ \\
\hline Short ( $\leq 6$ months $)$ & $24(15 \%)$ \\
\hline Long (> 6 months) & $122(75 \%)$ \\
\hline
\end{tabular}

${ }^{1}$ TURP: transurethral resection of the prostate; ${ }^{2}$ EBRT: external beam radiotherapy

therapy for 6 months (short-term hormone therapy). In high risk patients neoadjuvant-concomitant-adjuvant hormone therapy was given for 24-36 months (long-term hormone therapy). For patient immobilization supine or prone position is recommended [24]. In this study planning computed tomography (CT) imaging was performed in supine position using knee and ankle fixation support system for immobilization of the legs. Patients arms laid on their chest. Axial images were obtained with $3-5 \mathrm{~mm}$ slice thickness from L1 vertebra to about $3 \mathrm{~cm}$ below the ischial tuberosities. Before planning CT, patients were instructed to have moderately,comfortablyfilled bladder by drinking 0.51 of water (after having it emptied) half an hour prior to $\mathrm{CT}$ and an emptyrectum. In case of habitual constipation light laxative was recommended. Four tattoos were marked on the skin at the time of planning CT.

The rectum, bladder and hip joints were contoured as organs at risk (OARs). For intermediate risk 2 clinical target 
volumes were defined. The prostate clinical target volume (CTV_pros) included the whole prostate gland. The prostate and seminal vesicles CTV (CTV_psv) was generated by $5 \mathrm{~mm}$ expansion of CTV_pros in all directions except posteriorly at the prostate-rectum interface + proximal $1 \mathrm{~cm}$ of the seminal vesicles.

For high risk patients CTV_pros was the same as above. CTV_psv was defined by $5 \mathrm{~mm}$ expansion of CTV_pros in all directions except posteriorly + proximal $2 \mathrm{~cm}$ of seminal vesicles (in case of cT3b the entire seminal vesicles were included). Whole pelvis clinical target volume (CTV_pelv) consisted of CTV_psv + common iliac (under L5-S1 space), external iliac, presacral and obturator lymph nodes [25]. CTV_psv margins around CTV_pros were defined according to Chao et al. [26]. After analyzing a large number of prostatectomy specimens they found $\geq 4 \mathrm{~mm}$ extra capsular extension in $13 \%$ and $19 \%$ of the specimens in intermediate and high risk disease respectively.

Image guidance was performed using fiducial markers when pelvic irradiation was not required and with mega- or kilovoltage cone beam CT (MV or KV CBCT) in case of WPRT. During the whole treatment course daily orthogonal kilovoltage portal images were performed and fiducial markers were used for verification and online correctionof patients' setup. In the WPRT group or in the cases of lacking fiducials CBCT and online correctionof patients' setup was performed before the first 3 fractions. After the systematic error was calculated, isocentre was modified to exclude the systematic error, and thereafter CBCT based IGRT was used weekly for the rest of treatment. According to our institutional analysis, PTV margins with the use of fiducial and CBCT were $5 \mathrm{~mm}$ and $8 \mathrm{~mm}$ in every direction respectively.

All patients were treatedin 28 fractions with "step and shoot" IMRT or Volumetric Modulated Arc Therapy (VMAT) using 6-10 MV photon beams from Artiste (Siemens Medical Solutions Inc., USA) or TrueBeam and VitalBeam (Varian Medical Systems, Palo Alto, USA) linear accelerators, respectively.

Intermediated risk patients received $70 \mathrm{~Gy}$ to PTV_pros in $2.5 \mathrm{~Gy} /$ fraction $(\mathrm{EQD} 2=80 \mathrm{~Gy})$ and 57.4 Gyto PTV_psv in $2.05 \mathrm{~Gy} /$ fraction $(\mathrm{EQD} 2=58.2 \mathrm{~Gy})$. High risk and lymph node positive patients received 70 Gy to PTV pros, 57.4Gy to PTV_psv and 50.4 Gy to the pelvic lymph nodesusing $1.8 \mathrm{~Gy} /$ fraction. For PTV coverage, the $95 \%$ of the prescribed dose was requested to cover $95 \%$ of the target volume $\left(\mathrm{V}_{95 \%}>95 \%\right)$ for all PTVs. Rectum $\mathrm{V}_{45 \mathrm{~Gy}}, \mathrm{~V}_{63 \mathrm{~Gy}}$, bladder $\mathrm{V}_{45 \mathrm{~Gy}}$, hip joints $\mathrm{V}_{45 \mathrm{~Gy}}$ was constrained below $50 \%, 20 \%$, $65 \%$ and $10 \%$ of their volumes respectively. Dose constraint was not used regarding the small bowels. In Fig. 1 dose distribution is shown for the three target volumes in a high risk prostate cancer patient.

Patients were evaluatedevery second week during the treatment, every three months after radiation therapy for the first year and every 6 months thereafter. Acute and late genitourinary (GU) and gastrointestinal (GI) toxicities were scored according to the Radiation Therapy Oncology Group (RTOG) scoring system. Acute toxicities were reported during radiation therapy or within the initial 3-month follow-up.

Biochemical relapse free survival (bRFS) and cancer specific survival (CSS) curves were calculated using the KaplanMeier method. Spearman rank order and Chi-squared tests were used to evaluate the correlations between pelvic irradiation, method of image guidance, transurethral resection of prostate (TURP), hormone therapy, different dosimetric parameters of rectum, bladder, hip joints and acute GI, GU toxicities. Kaplan-Meier method and Gehan-Wilcoxon tests were used to evaluate the effects of pelvic irradiation, method of image guidance, TURP, hormone therapy on toxicity free survival. Logistic linear and Cox regressions were used in multivariate analysis to evaluate the prognostic factors of acute and late toxicities.

\section{Results}

Of 162 patients 156 (96\%) completed the moderately hypofractionated radiotherapy with SIB technique as planned. Seventy-eight patients (48.2\%) were treated with WPRT, 84 patients $(51,8 \%)$ with no WPRT. Six patients due to their age (74-82 year) and acute GU or GI grade 2 side effects received only 27 fractions ( $67.5 \mathrm{~Gy}$ to the prostate in $2.5 \mathrm{~Gy}$ fractions). Median follow-up was 30 months (range: 21-45).

The dosimetric data of the treatment plans are detailed in Table 2.Our dose constrains for rectum and hip joints have been reached in every patient. In 7 patients $(4.3 \%)$ bladder $\mathrm{V}_{45}$ was $>65 \%$ because of their relatively empty bladder at time of planning CT. Due to pre-treatment urinary symptoms these patients could not achieve filled bladder. IGRT was performed with fiducial markers, $\mathrm{kV} \mathrm{CBCT}$ or MV CBCT in $32.7 \%, 61.1 \%$ and $6.2 \%$ of the patients, respectively."Step and shoot" IMRT and VMAT techniques were applied in $6.2 \%$ and $93.8 \%$ of patients, respectively.

Acute and late toxicities are reported in Table 3.In general, urinary toxicity resolved spontaneously or with the administration of non-steroidal anti-inflammatory or $\alpha 1$ blockermedications. Six patients (4\%) presented grade 3 late GU toxicity and 8patients (5\%) grade 3 late GI toxicity. None of the patients experienced acute or late grade 4 side effects.

We found no correlation between acute or late toxicity andthe use of WPRT, previous urological surgery or modality of IGRT.

Crude rate of biochemicalrelapse free survival and cancer specific survival was $98 \%$ and 99\%, respectively (Figs. 2 and 3 ). No in-field lymph node recurrence was observed. Three patients (2\%) developed multiplex bone metastases, currently one of them is receiving chemotherapy, 2 patients 


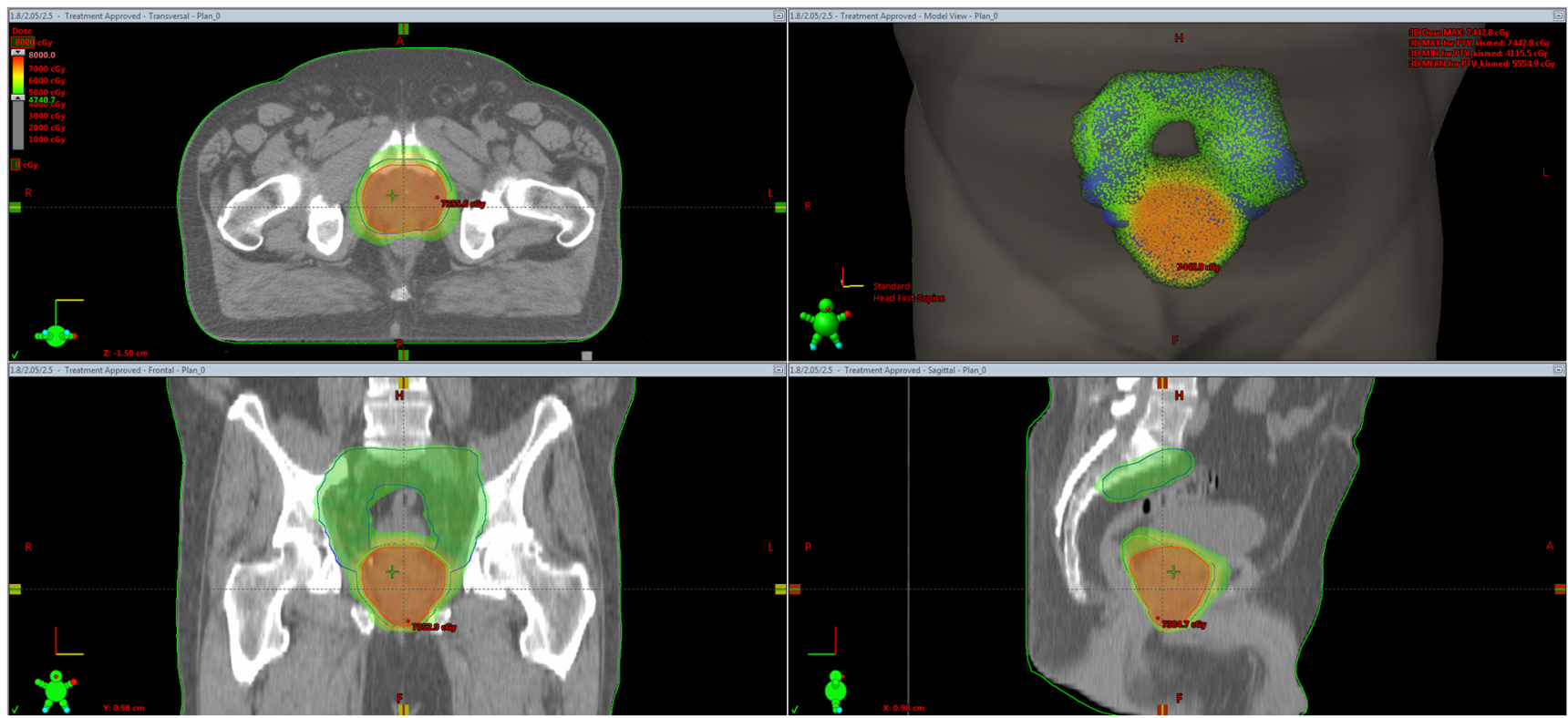

Fig. 1 Representative dose distributions of a VMAT plan for high risk prostate cancer patient with whole pelvis irradiation in axial, sagittal, coronal and $3 \mathrm{D}$ views

(1\%) died due to disease progression. Six (4\%) patients died from non-prostate cancer disease.

No correlation was found between WPRT vs. no WPRT, method of image guidance, TURP vs. no TURP, length of hormone therapy or the different dosimetric parameters of rectum, bladder, hip joints and acute GI, GU toxicities. Significant correlation was found between acute GI and acute GU toxicities, between acute GI and cumulative late GI and between acute $\mathrm{GU}$ and cumulative late GU toxicities $(p<0.05)$.

With Gehan-Wilcoxon test only a non-significant trend was observed for late GI toxicities in favour of image guidance with gold markers compared to CBCT based methods. For other parameters significant effects on toxicity were not found. In multivariate analysis no significant predictor was found for acute or late GI or GU toxicities.

\section{Discussion}

Based on the radiobiological assumption that prostate cancer has a high sensitivity to fraction dose, due to a low $\alpha / \beta$ ratio (1.5Gy), several randomized trials were published, using a

Table 2 Dose constraints and dosimetric parameters of organs at risk

\begin{tabular}{lll}
\hline Dosimetric parameter & Dose constraint (\%) & Mean \% (range) \\
\hline Rectum $\mathrm{V}_{45 \mathrm{~Gy}}$ & 50 & $29.8(11-49)$ \\
Rectum $\mathrm{V}_{63 \mathrm{~Gy}}$ & 20 & $9.5(2-19)$ \\
Bladder $\mathrm{V}_{45 \mathrm{~Gy}}$ & 65 & $36.4(0.1-80)$ \\
Hip joints $\mathrm{V}_{45 \mathrm{~Gy}}$ & 10 & $1.3(0.1-9)$ \\
\hline
\end{tabular}

superiority (Regina Elena, Fox Chase, MD Anderson, HYPRO) and non-inferiority (NRG Oncology, CHHiP, PROFIT) design to compare moderate hypofractionation (dose per fraction 2.4-3.5 Gy) to conventional fractionation (dose per fraction 1.8-2 Gy) [27-35]. Both in superiority and non-inferiority trials the rate of late toxicity was similar with moderate hypofractionation compared to conventional fractionation provided that the dose per fraction was kept below 3 Gy. However, only in one of these trials (Fox Chase trial) the high risk patients were treated with WPRT. In this superiority randomized trial 303 patients received either 76 Gy in $2 \mathrm{~Gy} /$ fraction over 7.5 weeks or $70.2 \mathrm{~Gy}$ in $2.7 \mathrm{~Gy} /$ fraction while the pelvis was treated up to $56 \mathrm{~Gy}$ in 38 fractions in the conventional arm and up to $50 \mathrm{~Gy}$ in 26 fractions in the hypofractionated group. GI grade 3 toxicities occurred in $2 \%$ in both treatment arms, while GU grade 3 toxicities were observed in $3.3 \%$ and in $4 \%$, respectively.

In high risk prostate cancer there is still considerable controversy in the literature regarding the role of elective pelvic

Table 3 Acute and cumulative late toxicities

\begin{tabular}{llll}
\hline Toxicity & Grade & $\begin{array}{l}\text { Acute toxicity } \\
(\%) N=162\end{array}$ & $\begin{array}{l}\text { Late toxicity } \\
(\%) \mathrm{N}=162\end{array}$ \\
\hline Gastrointestinal & 0 & 27 & 83 \\
& 1 & 51 & 6 \\
Genitourinary & 2 & 21 & 6 \\
& 3 & 1 & 5 \\
& 0 & 11 & 68 \\
& 1 & 31 & 15 \\
& 2 & 57 & 13 \\
& 3 & 1 & 4
\end{tabular}




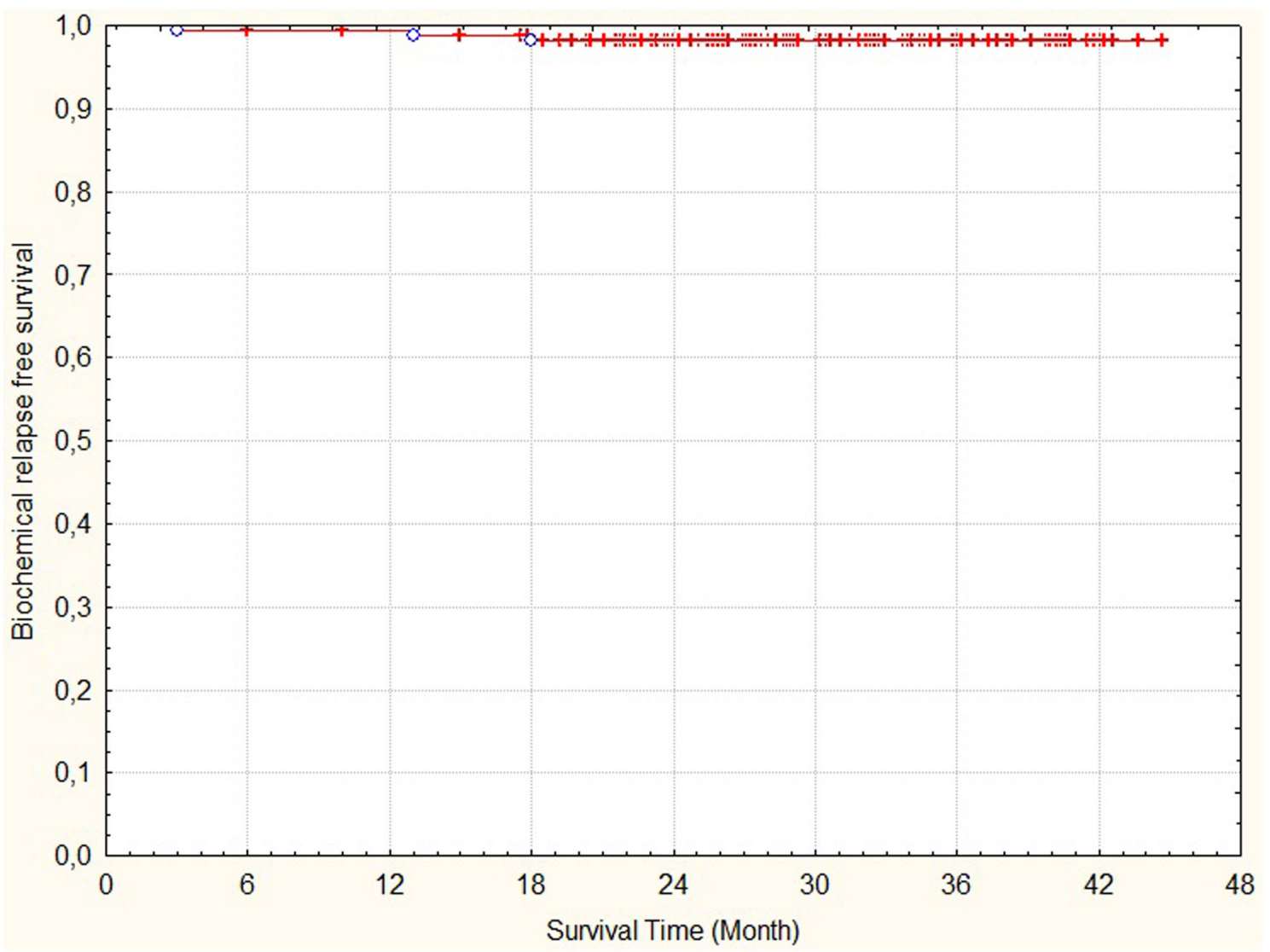

Fig. 2 Time to biochemical failure

node irradiation. In these patients there is a high probability of occult, radiologically undetectable lymph node metastases [8]. Based on the results of a randomized, phase III study comparing prostate only radiation therapy with WPRT, a trend to increased progression free survival was demonstrated in the group of patients with $>15 \%$ probability of lymph node metastasis treated with WPRT $[36,37]$. Another open issue regardingWPRT is the potential increase of toxicity, because of the larger irradiated volume compared to prostate only radiotherapy. Recently, several trials reported reduction of GI side effects using IMRT for irradiation of the pelvic lymph nodes $[37,38]$. In the current trial none of the patient experienced grade 4 toxicity. Of 162 patients $2(1 \%)$ developed acute GI and GU grade 3 side effects, late GI and GU grade 3 toxicities occurred in $8(5 \%)$ and $6(4 \%)$ patients, respectively.

Di Muzio et al. $[39,40]$ recently published their 5-year results of moderately hypofractionated radiation therapy with SIB to the prostate. Intermediate and high risk patients received 51.8Gy to pelvic nodes and concomitant SIB to the prostate up to $74.2 \mathrm{~Gy}$ in 28 fractions. Low risk patients were treated to the prostate only with $71.4 \mathrm{~Gy}$ in 28 fractions. Among 211 patients the incidence of acute GU grade 2 and grade 3 toxicity was $29 \%$ and $1.9 \%$, respectively, GI grade 2 and grade 3 toxicity occurred in $6.2 \%$ and $0.5 \%$, respectively. Late GU grade $\geq 2$ and grade $\geq 3$ toxicity was $20.2 \%$ and $5.9 \%$, late GI grade $\geq 2$ and grade $\geq 3$ toxicity $17 \%$ and $6.3 \%$ respectively. One patient experienced grade 4 toxicity (cystectomy).

Saracino et al. [41] reported 5-year results in 110 high risk patients treated with WPRT and SIB to the prostate. The 3and 5-year rate of grade $\geq 2$ late GI toxicity was $2 \%$ and $5 \%$, respectively, while the 3 - and 5-year rate of grade $\geq 2$ late GU toxicity was $5 \%$ and $12 \%$, respectively. The rate of grade 2 acute rectal, intestinal and genitourinary toxicities were $40 \%$, $23 \%$, and $39 \%$, respectively, and none of the patients experienced grade 3 toxicity [42].

Franzese et al. [43] reported the results of 90 high risk patients treated with moderately hypofractionated radiotherapy with SIB. At 25 months late grade 2 and 3 GI toxicitywas observed in $1 \%$ and $0 \%$, respectively. The rates of developing any late $\mathrm{GU}$ grade 2 or 3 toxicity were $6 \%$ and $1 \%$, respectively.

The results of other important trials using WPRT combined with SIB to the prostate areshown in Table 4.

In our prospective study with large number of patients, the toxicity rates compare favourably with similar trials using WPRT with SIB to the prostate. Despite the fact that in WPRT group the irradiated volume was larger compared to no WPRT group, no correlation was found between WPRT vs. no WPRT and acute GI, GU toxicities. To our opinion, the improved dose distribution of IMRT plans allowing a reduced dose bath to the rectum and the accurate IGRT techniques may 


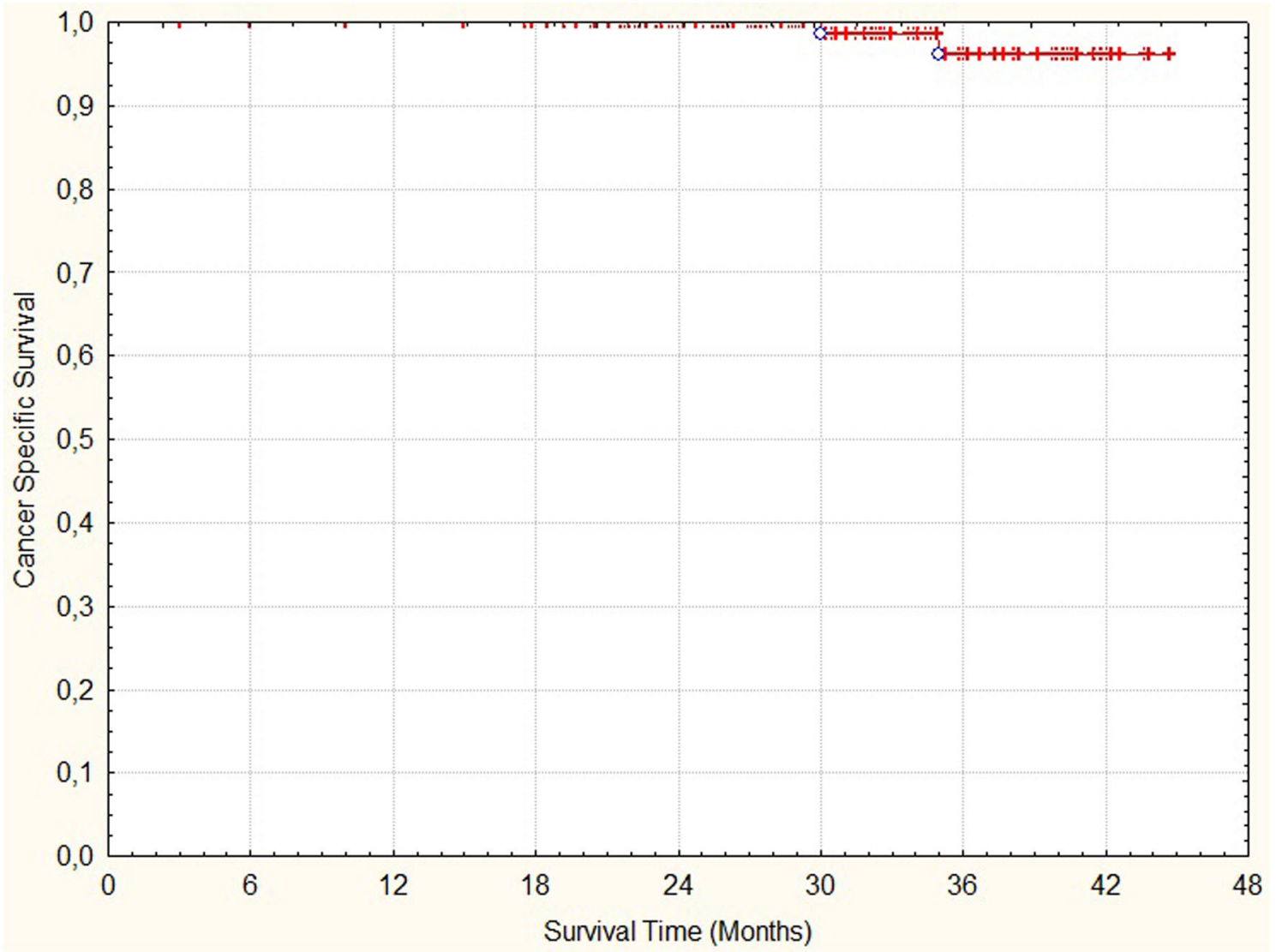

Fig. 3 Time to prostate cancer death

Table 4 Results of clinical trials using whole pelvis radiation therapy (WPRT) combined with simultaneous integrated boost (SIB) to the prostate. SV: seminal vesicles

\begin{tabular}{|c|c|c|c|c|c|c|c|c|c|}
\hline \multirow[t]{2}{*}{ Reference } & \multirow[t]{2}{*}{ No. patients } & \multirow[t]{2}{*}{$\begin{array}{l}\text { Total dose/fraction } \\
\text { dose (Gy) }\end{array}$} & \multirow[t]{2}{*}{ No. fractions } & \multirow[t]{2}{*}{$\begin{array}{l}\text { Median follow-up } \\
\text { (months) }\end{array}$} & \multicolumn{2}{|c|}{$\begin{array}{l}\text { Acute toxicity } \\
\text { grade } \geq 3(\%)\end{array}$} & \multicolumn{2}{|c|}{$\begin{array}{l}\text { Late toxicity } \\
\text { grade } \geq 3(\%)\end{array}$} & \multirow[t]{2}{*}{$\begin{array}{l}\text { Biochemica } \\
\text { control }(\%)\end{array}$} \\
\hline & & & & & GU & GI & GU & GI & \\
\hline McCammon, 2008 [44] & 30 & $\begin{array}{l}\text { pelvis: } 50.4 / 1,8 \\
\text { prostate: } 70 / 2.5\end{array}$ & 28 & 24 & 0 & 3.3 & 0 & 10 & - \\
\hline Engels, 2009 [45] & 28 & $\begin{array}{l}\text { pelvis: } 54 / 1.8 \\
\text { prostate: } 70.5 / 2.35\end{array}$ & 30 & 10 & 4 & 0 & - & - & - \\
\hline Adkison, 2010 [46] & 53 & $\begin{array}{l}\text { pelvis: } 56 / 2 \\
\text { prostate: } 70 / 2.5\end{array}$ & 28 & 25 & 0 & 0 & 2 & 0 & 81 \\
\hline Alongi, 2012 [47] & 70 & $\begin{array}{l}\text { pelvis: } 51.8 / 1.85 \\
\text { prostate: } 74.2 / 2.65\end{array}$ & 28 & 11 & 1 & 0 & - & - & - \\
\hline Pollack, 2013 [28] & 303 & $\begin{array}{l}\text { pelvis: } 50 / 1.92 \\
\text { prostate: } 70.2 / 2.7\end{array}$ & 26 & 68 & - & - & 4 & 2 & 76.7 \\
\hline Saracino, 2014 [41] & 37 & $\begin{array}{l}\text { pelvis: } 57 / 1.56 \\
\text { prostate: } 80 / 2\end{array}$ & 40 & 56 & 0 & 0 & 0 & 0 & 90 \\
\hline Di Muzio, 2016 [40] & 211 & $\begin{array}{l}\text { pelvis: } 51.8 / 1.85 \\
\text { prostate: } 74.2 / 2.65\end{array}$ & 28 & 60 & 1.9 & 0.5 & 5.9 & 6.3 & 95 \\
\hline Franzese, 2017 [43] & 90 & $\begin{array}{l}\text { pelvis: } 51.8 / 1.8 \\
\text { SV: } 65.5 / 2.34 \\
\text { prostate: } 74.2 / 2.65\end{array}$ & 28 & 25 & 2 & 0 & 1 & 0 & 90 \\
\hline Chang, 2017 [48] & 55 & $\begin{array}{l}\text { pelvis: } 50.4 / 1.68 \\
\text { SV: } 54 / 1.8 \\
\text { prostate: } 72 / 2.4\end{array}$ & 30 & 24 & - & - & 6 & 2 & 96 \\
\hline Magli, 2017 [49] & 41 & $\begin{array}{l}\text { pelvis: } 50 / 2 \\
\text { SV: } 56.25 / 2.25 \\
\text { prostate: } 67.5 / 2.7\end{array}$ & 25 & 60 & 0 & 0 & 0 & 0 & 95 \\
\hline Present study & 162 & $\begin{array}{l}\text { pelvis: } 50.4 / 1.8 \\
\text { SV: } 57.4 / 2.05 \\
\text { prostate: } 70 / 2.5\end{array}$ & 28 & 30 & 1 & 1 & 4 & 5 & 98 \\
\hline
\end{tabular}


be the explanation of the finding above. Another result of our trial is that treatment side effects did not correlate with IGRT regimens (fiducial, $\mathrm{kV} \mathrm{CBCT}$ or $\mathrm{MV} \mathrm{CBCT}$ ).

At 30-month follow-up time we experienced excellent biochemical control $(98 \%)$.

There are several limitations of our study. One is the relatively short follow-up time. Longer follow-up is necessary to evaluate long-term toxicity and biochemical control. Another limitation is the lack of patient-reported toxicity,therefore we may underestimate the toxicity rates. Furthermore, this study was not a randomized one. We did not compareour SIB treatment protocol to a conventionally fractionated treatment schedule.

\section{Conclusion}

WPRT with SIB tothe prostate, seminal vesicles or positive pelvic lymph nodes is a feasible and safe technique for patientswith intermediate and high risk localized, locally advanced and node positiveprostate cancer. According to our results this treatment seems to be associated with a tolerable frequency and severity of acute GU and GI toxicities. The rate of severe late GI and UG toxicities are low and comparable to rates with conventionally fractionated treatments. This technique provides shorter overall treatment time compared to conventional fractionation thus sparing treatment capacity on the linear accelerator. Additional validation with a longer follow-up is needed.

Funding Information Open access funding provided by National Institute of Oncology (OOI).

\section{Compliance with Ethical Standards}

Conflict of Interest The authors declare that they have no conflict of interest.

Ethical Approval This article has not been published before, it is not under consideration for publication anywhere else. This publication has been approved by all co-authors.

Open Access This article is distributed under the terms of the Creative Commons Attribution 4.0 International License (http:// creativecommons.org/licenses/by/4.0/), which permits unrestricted use, distribution, and reproduction in any medium, provided you give appropriate credit to the original author(s) and the source, provide a link to the Creative Commons license, and indicate if changes were made.

\section{References}

1. Kuban DA, Tucker SL, Dong L et al (2008) Long-term results of the M.D. Anderson randomized dose-escalation trial for prostatecancer. Int J Radiat Oncol Biol Phys 70:67-74
2. Peeters ST, Heemsbergen WD, Koper PC et al (2006) Doseresponsein radiotherapy for localized prostate cancer: results of theDutch multicenter randomized phase III trial comparing 68Gy of radiotherapy with 78 Gy. J Clin Oncol 24:1990-1996

3. Zietman AL, DeSilvio ML, Slater JD et al (2005) Comparison of conventional-dose vs. high-dose conformal radiation therapyin clinically localized adenocarcinoma of the prostate: a randomized controlled trial. JAMA 294:1233-1239

4. Miralbell R, Roberts SA, Zubizarreta E et al (2012) Dose-fractionation sensitivity of prostate cancer deduced from radiotherapy outcomes of 5 , 969 patients in seven international institutional datasets: $\alpha / \beta=1.4$ (0.9 2.2) Gy. Int J Radiat Oncol Biol Phys 82:1017-1024

5. Brenner DJ, Hall EJ (1999) Fractionation and protraction for radiotherapy of prostate carcinoma. Int J Radiat Oncol Biol Phys 43:1095-1101

6. Tree AC, Khoo VS, van As NJ et al (2014) Is biochemical relapse-free survival after profoundly hypofractionated radiotherapy consistent with current radiobiological models? Clin Oncol 26:216-229

7. Lee WR, Koontz BF (2018) Moderate hypofractionation for prostate cancer. Transl Androl Urol 7:321-329

8. Roach M III (1993) Re: the use of prostate specific antigen, clinical stage and Gleason score to predict pathological stage in men with localized prostate cancer. J Urol 150:1923-1924

9. Joniau S, Van den Bergh L, Lerut E et al (2013) Mapping of pelvic lymph node metastases in prostate cancer. Eur Urol 63:450-458

10. Heidenreich A, Varga Z, Von Knobloch R (2002) Extended pelvic lymphadenectomy in patients undergoing radical prostatectomy: high incidence of lymph node metastasis. J Urol 167:1681-1686

11. Bader P, Burkhard FC, Markwalder R et al (2002) Is a limited lymph node dissection an adequate staging procedure for prostate cancer? J Urol 168:514-518

12. Wyler SF, Sulser T, Seifert HH, Ruszat R, Forster TH, Gasser TC, Bachmann A (2006) Laparoscopic extended pelvic lymph node dissection for high-risk prostate cancer. Urology 68:883-887

13. Arenas LF, Füllhase C, Boemans P et al (2010) Detecting lymph nodes metastasis in prostate cancer through extended vs. standard laparoscopic pelvic lymphadenectomy. Aktuelle Urol 41:S10-S14

14. Seaward SA, Weinberg V, Lewis P, Leigh B, Phillips TL, Roach M III (1998) Improved freedom from PSA failure with whole pelvic irradiation for high-risk prostate cancer. Int J Radiat Oncol Biol Phys 42:1055-1062

15. Seaward SA, Weinberg V, Lewis $P$ et al (1998) Identification of a highrisk clinically localised prostate cancer subgroup receiving maximum benefit from whole pelvic irradiation. Cancer J Sci Am 4:370-377

16. Pan CC, Kim KY, Taylor JM et al (2002) Influence of 3D-CRT pelvic irradiation on outcome in prostate cancer treated with external beam radiotherapy. Int J Radiat Oncol Biol Phys 53:1139-1145

17. Aizer AA, Yu JB, McKeon AM et al (2009) Whole pelvic radiotherapy versus prostate only radiotherapy in the management of locally advanced or aggressive prostate adenocarcinoma. Int J Radiat Oncol Biol Phys 75:1344-1349

18. Milecki P, Baczyk M, Skowronek J et al (2009) Benefit of whole pelvis radiotherapy combined with neoadjuvant androgen deprivation for the high-risk prostate cancer. J Biomed Biotechnol 2009:625394

19. Mantini G, Tagliaferri L, Mattiucci GC et al (2011) Effect of whole pelvic radiotherapy for patients with locally advanced prostate cancer treated with radiotherapy and long-term androgen deprivation therapy. Int J Radiat Oncol Biol Phys 81:721-726

20. Asbell SO, Martz KL, Shin KH et al (1998) Impact of surgical staging in evaluating the radiotherapeutic outcome in RTOP 7706 , a phase III study for T1bN0M0 (A2) and T2N0M0 (B) prostate carcinoma. Int J Radiat Oncol Biol Phys 40:769-782

21. Lawton CA, DeSilvio M, Roach M et al (2007) An update of the phase III trial comparing whole-pelvic to prostate-only radiotherapy and neo-adjuvant to adjuvant total androgen suppression: updated analysis of RTOG 94-13, with emphasis on unexpected hormone/ radiation interactions. Int J Radiat Oncol Biol Phys 69:646-655 
22. Pommier P, Chabaud S, Lagrange JL et al (2007) Is there a role for pelvic irradiation in localized prostate adenocarcinoma? Preliminary results of GETUG-01. J Clin Oncol 25:5366-5373

23. D'Amico AV, Moul J, Carroll PR et al (2003) Cancer-specific mortality after surgery orradiation for patients with clinically localized prostate cancer managed during the prostate-specific antigen era. $\mathrm{J}$ Clin Oncol 21:2163-2172

24. Kószó, R., Varga, L., Fodor, E., Kahán Z., Cserháti A., Hideghéty K., Együd Z., Szabó C., Borzási E., Szabó D., Müllner K., Varga Z., Maráz A. (2018) Prone positioning on a belly board decreases rectal and bowel doses in pelvic intensity-modulated radiation therapy (IMRT) for prostate. Cancer Pathol Oncol Res https://doi.org/10. 1007/s12253-018-0436-2

25. Lawton CA, Michalski J, El-Naqa I et al (2009) RTOG GU radiation oncology specialists reach consensus on pelvic lymph node volumes for high-risk prostate cancer. Int J Radiat Oncol Biol Phys 74:383-387

26. Chao KK, Goldstein NS, Yan D, Vargas CE, Ghilezan MI, Korman HJ, Kernen KM, Hollander JB, Gonzalez JA, Martinez AA, Vicini FA, Kestin LL (2006) Clinicopathologic analysis of extracapsular extension in prostate cancer: should the clinical target volume be expanded posterolaterally to account for microscopic extension? Int J Radiat Oncol Biol Phys 65:999-1007

27. Arcangeli G, Saracino B, Arcangeli S et al (2017) Moderate hypofractionation in high-risk, organ-confined prostate cancer: final results of a phase III randomized trial. J Clin Onco 135:1891-1897

28. Pollack A, Walker G, Horwitz EM, Price R, Feigenberg S, Konski AA, Stoyanova R, Movsas B, Greenberg RE, Uzzo RG, Ma C, Buyyounouski MK (2013) Randomized trial of hypofractionated external beam radiotherapy for prostate cancer. J Clin Oncol 31:3860-3868

29. Hoffman KE, Voong KR, Levy LB, Pugh TJ, Choi S, du W, Frank SJ, Johnson JL, Kudchadker R, Nguyen QN, Lee A, Mahmood U, McGuire SE, Kuban DA (2016) Randomized trial of hypofractionated dose-escalated intensity modulated radiation therapy versus conventionally fractionated intensity modulated radiation therapy for localized prostate cancer. Int J Radiat Oncol Biol Phys 96:S32

30. Incrocci L, Wortel RC, Alemayehu WG et al (2016) Hypofractionated versus conventionally fractionated radiotherapy for patients with localized prostate cancer (HYPRO): final efficacy results from a randomized, multicentre, open-label, phase 3 trial. Lancet Oncol 17:1061-1069

31. Aluwini S, Pos F, Schimmel E et al (2016) Hypofractionated versus conventionally fractionated radiotherapy for patients with prostate cancer (HYPRO): late toxicity results from a randomized, non-inferiority, phase 3 trial. Lancet Oncol 17:464-474

32. Lee WR, Dignam JJ, Amin MB, Bruner DW, Low D, Swanson GP, Shah AB, D’Souza DP, Michalski JM, Dayes IS, Seaward SA, Hall WA, Nguyen PL, Pisansky TM, Faria SL, Chen Y, Koontz BF, Paulus R, Sandler HM (2016) Randomized phase IIInoninferiority study comparing two radiotherapy fractionation schedules in patients with low-risk prostate cancer. J Clin Oncol 34:2325-2332

33. Dearnaley D, Syndikus I, Mossop H et al (2016) Conventional versus hypofractionated high-dose intensity-modulated radiotherapy for prostate cancer: 5-year outcomes of the randomised, noninferiority, phase 3CHHiP trial. Lancet Oncol 17:1047-1060

34. Wilkins A, Mossop H, Syndikus I et al (2015) Hypofractionated radiotherapy versus conventionally fractionated radiotherapy for patients with intermediate-risk localized prostate cancer: 2-year patient-reported outcomes of the randomized, non-inferiority, phase 3CHHiP trial. Lancet Oncol 16:1605-1616

35. Catton CN, Lukka H, Gu CS, Martin JM, Supiot S, Chung PWM, Bauman GS, Bahary JP, Ahmed S, Cheung P, Tai KH, Wu JS, Parliament MB, Tsakiridis T, Corbett TB, Tang C, Dayes IS, Warde P, Craig TK, Julian JA, Levine MN (2017) Randomized trial of a hypofractionated radiation regimen for the treatment of localized prostate cancer. J Clin Oncol 35:1884-1890

36. Roach M, DeSilvio M, Lawton C et al (2003) Radiation therapy oncology group 9413. Phase III trial comparing whole pelvic versus prostate only radiotherapy and neoadjuvant versus adjuvant combined androgen suppression: radiation therapy oncology group 9413. J Clin Oncol 21:1904-1911

37. Lawton CA, DeSilvio M, Roach M et al (2007) An update of the phase III trial comparing whole pelvic to prostate only radiotherapy and neoadjuvant to adjuvant total androgen suppression: updated analysis of RTOG 94-13, with emphasis on unexpected hormone/ radiation interactions. Int J Radiat Oncol Biol Phys 69:646-655

38. Cozzarini C, Fiorino C, Muzio D et al (2007) Significant reduction of acute toxicity following pelvic irradiation with helical Tomotherapy in patients with localized prostate cancer. Radiother Oncol 84:164-170

39. Di Muzio N, Fiorino C, Cozzarini C et al (2009) Phase I-II study of hypofractionated simultaneous integrated boost with tomotherapy for prostate cancer. Int J Radiat Oncol Biol Phys 74:392-398

40. Di Muzio NG, Fodor A, Noris B et al (2016) Moderate Hypofractionation with simultaneous integrated boost in prostate Cancer: long-term results of a phase I/II study. Clin Oncol 28:490-500

41. Saracino B, Petrongari MG, Marzi S et al (2014) Intensitymodulatedpelvic radiation therapy and simultaneous integrated boost tothe prostate area in patients with high-risk prostate cancer: apreliminary report of disease control. Cancer Med 3:1313-1321

42. Arcangeli G, Saracino B, Petrongari MG et al (2007) Analysis of toxicity in patients with high risk prostate cancer treated with intensity-modulated pelvic radiation therapy and simultaneous integrated dose escalation to prostate area. Radiother Oncol 84:148-155

43. Franzese C, Fogliata A, D'Agostino GR et al (2017) Moderate hypofractionated radiotherapy with volumetric modulated arc therapy and simultaneous integrated boost for pelvic irradiation in prostate cancer. J Cancer Res Clin Oncol 143:1301-1309

44. McCammon R, Rusthoven KE, Kavanagh B et al (2009) Toxicity assessment of pelvic intensity-modulated radiotherapy with hypofractionated simultaneous integrated boost to prostate for intermediate- and high-risk prostate cancer. Int J Radiat Oncol Biol Phys 75:413-420

46. Engels B, Soete G, Tournel K et al (2009) Helical tomotherapy with simultaneous integrated boost for high risk and lymph node positiveprostate cancer: early report on acute and late toxicity. Technol Cancer Res Treat 8:353-9

48. Adkison JB, McHaffie DR, Bentzen SM et al (2012) Phase I trial of pelvic nodal dose escalation with hypofractionated IMRT for highrisk prostate cancer. Int J Radiat Oncol Biol Phys 82:184-190

49. Alongi F, Fogliata A, Navarria P et al (2012) Moderate hypofractionation and simultaneous integrated boost with volumetric modulated arc therapy (RapidArc) for prostate cancer. Report of feasibility and acute toxicity. Strahlenther Onkol 188:990-996

50. Chang MG, Mukhopadhyay N, Holdford D, Skinner V, Saraiya S, Moghanaki D, Anscher MS (2018) Phase 1/2 study of hypofractionated intensity-modulated radiation therapy for prostate cancer including simultaneously integrated boost. Pract Radiat Oncol 8:e149-e157

51. Magli A, Moretti E, Tullio A, Giannarini G, Tonetto F, Urpis M, Crespi M, Foti C, Prisco A, Polsinelli M, de Giorgi G, Bravo G, Scalchi P, Trovò M (2018) Hypofractionated simultaneous integrated boost (IMRT-SIB) with pelvic nodal irradiation and concurrent androgen deprivation therapy for high-risk prostate cancer: results of a prospective phase II trial. Prostate Cancer Prostatic Dis 21:269-276

Publisher's Note Springer Nature remains neutral with regard to jurisdictional claims in published maps and institutional affiliations. 